\title{
ASPECTOS SOCIOAMBIENTAIS DO NÚCLEO DE DESERTIFICAÇÃO DE SÃO RAIMUNDO NONATO/PIAUÍ
}

\author{
socioenvironmental aspects of the nucleus of desertification of São Raimundo Nonato/Piauí
}

\author{
Cláudia Maria Sabóia de Aquino* \\ José Antonio Pacheco de Almeida** \\ José Gerardo Beserra de Oliveira***
}

\begin{abstract}
Resumo
A cobertura vegetal é, dentre os componentes ambientais, um dos mais afetados pelas ações humanas. Como conseqüência da má utilização deste recurso natural tem-se o comprometimento do regime das águas, das características dos solos, dos processos de escoamento superficial, culminando com a erosão. Diante da importância da cobertura vegetal, este trabalho objetivou analisar de forma têmporo-espacial a dinâmica da cobertura das terras, do NDVI e de dados econômicos para fins de avaliação da degradação/desertificação no Núcleo de São Raimundo Nonato. Os resultados mostraram que houve decréscimo significativo da classe de cobertura das terras do tipo agricultura+solos exposto. Os dados de NDVI também evidenciaram decréscimo da classe solo exposto. Na classe de proteção muito baixa houve incremento, esta passou de $71,8 \%$, em 1987, para $86 \%$ em 2007. O aumento da proteção oferecida pela cobertura vegetal que em 1987 era de $15,7 \%$ passou para $17,5 \% \mathrm{em} 2007$. Os resultados econômicos indicam a redução do tamanho dos rebanhos e das áreas cultivadas com culturas temporárias. Esta redução contribui positivamente para a diminuição do processo de degradação/desertificação na área de estudo.
\end{abstract}

Palavras-chave: Cobertura das Terras, NDVI, Indicadores Econômicos, Desertificação.

\begin{abstract}
Vegetation canopy is, among the environmental components, one of the most affected by human actions. As a result of the misuse of this natural resource,there's endangerment of water regimen, soil characteristics, surface runoff process, all this leading to erosion. Because of the importance of vegetation cover, this study has the objective to examine, in a time-space focus, the dynamics of vegetation cover/ land use, NDVI and economic data for assessment of degradation / desertification in the area of São Raimundo Nonato. The results have showed a significant decrease in the class of vegetation cover/land use of agriculture + soil exposed. NDVI data also showed a decrease in bare soil class. In the class of very little protection there was an increase. The increase of protection offered by that vegetation cover in 1987 was $15.7 \%$ and it went to $17.5 \%$ in 2007 . The economic results indicate reduction in the size of herds and of cultivated areas with seasonal crops. This reduction contributes positively to decrease the process of degradation / desertification in the área studied.
\end{abstract}

Keywords: Land Cover, NDVI, Economic Indicators, Desertification.

\begin{abstract}
Resumen
La cobertura vegetal es, entre los componentes ambientales, uno de los más afectados por las acciones humanas. Como consecuencia de una mala utilización de este recurso natural, se tiene el comprometimiento del régimen de las aguas, de las características de los suelos, de los procesos de reflujo superficial, culminando en la erosión. Delante de la importancia de la cobertura vegetal, este trabajo tuvo como objetivo analizar de forma temporal y espacial, la dinámica de la cobertura vegetal/uso de la tierra, del NDVI y de los datos económicos para fines de evaluación de la degradación/desertificación en el Núcleo de São Raimundo Nonato. Los resultados mostraron que hubo rebajas significativas de la clase de cobertura vegetal/uso de la tierra del tipo agricultura + suelos expuestos. Los datos de NDVI también mostraron rebajas de la clase suelo expuesto. En la clase de protección muy baja hubo incremento, esta pasó de 71,8\%, en 1987, para $86 \%$ en 2007. El aumento de la protección ofrecida por la cobertura vegetal que en 1987 era de $15,7 \%$ pasó para $17,5 \%$ en 2007. Los resultados económicos indican la reducción del tamaño de los rebaños y de las áreas cultivadas con culturas temporales. Esta reducción contribuye positivamente para la disminución del proceso de degradación/desertificación en el área de estudio.
\end{abstract}

Palabras claves: Cobertura Vegetal, Uso de la Tierra, NDVI, Indicadores Económicos, Desertificación.

(*) Prof ${ }^{a}$ Dr $^{\mathrm{a}}$ da Pós-Graduação em Geografia da Universidade Federal do Piauí - Campus Universitário Ministro Petrônio Portela, CEP 64049-550, Teresina (PI), Brasil, Tel: (+55 86) 32155777 - cmsaboia@gmail.com

(**) Prof. Dr. da Universidade Federal de Sergipe - Núcleo de Geologia, Campus Universitário s/n, CEP: 49100-000, Aracaju (SE), Brasil, Tel: (+55 79) 21056326 - pachecoalmeida@ig.com.br

$(* * *)$ Prof. Dr. da Universidade Federal do Ceará - Departamento de Biologia,Cx. Postal 6021, CEP: 60.455-970, Fortaleza, CE, Brasil, - Tel: (+55 85) 33669831 -jgboliv@gmail.com 


\section{INTRODUÇÃO}

De modo geral, a utilização inadequada de alguns recursos naturais fundamentais à vida, tais como o ar, a água e os solos, tem conduzido a transformações ambientais que podem ser identificadas a partir da superexploração dos solos, do comprometimento dos recursos hídricos em quantidade e qualidade, da perda e/ou redução da diversidade biológica, e ainda da redução da cobertura vegetal, resultando no empobrecimento dos ecossistemas, especialmente os áridos, semiáridos e os subúmidos secos com o consequente desencadeamento de áreas degradadas/desertificadas.

A utilização da cobertura vegetal como indicador nos estudos ambientais é ratificada a partir das afirmativas de Bertrand (2004), Vieira (1978) e de Vasconcelos Sobrinho (1978). Este último considera que o indicador biológico-agrícola mais importante da desertificação, são as modificações sofridas pela cobertura vegetal de plantas perenes durante a estação seca.

Considerando a afirmativa de Brasil (2004), de que o uso e ocupação das terras secas ao longo de várias décadas tem contribuído para o estabelecimento dos processos de desertificação e determinado a velocidade de sua ocorrência, objetivou-se neste trabalho: i) identificar e comparar a partir de técnicas de sensoriamento remoto a dinâmica entre os tipos de cobertura das terras no Núcleo de São Raimundo Nonato entre os anos de 1987 e 2007; ii) estabelecer relações entre os tipos de cobertura vegetal/uso da terra e o NDVI da área de estudo e ainda iii) relacionar os dados de cobertura das terras e de NDVI com os de produção agrícola e pecuária em uma perspectiva multitemporal, para fins de avaliação da degradação/desertificação no Núcleo de São Raimundo Nonato.

\section{MATERIAL E MÉTODOS}

\section{Área de estudo}

A área geográfica de estudo localiza-se na porção sudeste do Estado do Piauí, integrando a microrregião de São Raimundo Nonato. Distribui-se de forma descontínua entre as coordenadas

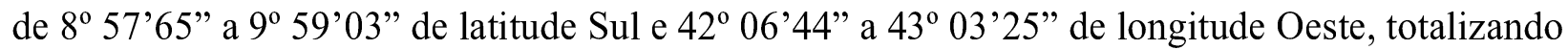
uma área de aproximadamente $6.988 \mathrm{~km} 2$.

O núcleo de São Raimundo Nonato é composto por cinco municípios: São Raimundo Nonato, Coronel José Dias, Bonfim do Piauí, São Lourenço e Dirceu Arcoverde (Figura 1)

Considerando a geologia regional, o Núcleo de São Raimundo Nonato situa-se em três grandes domínios geológicos: a Província São Franciscana, a Província Borborema e a Província Parnaíba. Quanto ao aspecto geomorfológico de acordo com Brasil (1973) a área de estudo exibe duas unidades morfoestruturais i) a superfície tabular estrutural representada por planaltos areníticos cuestiformes e ii) a superfície pediplanada pré-cambriana.

A análise climática da área de estudo baseou-se em dados de precipitação das séries anuais disponíveis em Sudene (1990). A análise dos dados revelou valores médios anuais de precipitação variando de $996 \mathrm{~mm}$ a $707 \mathrm{~mm}$.

A evapotranspiração potencial corresponde à chuva teoricamente necessária para atender ao consumo de água pela superfície vegetada, de forma a manter a folhagem sempre verde, ou seja, seria a chuva ideal para não resultar nem sobra nem falta de água no solo, apenas o suficiente para manter a vegetação turgescente e transpirando livremente o ano todo.

A evapotranspiração potencial (ETP) da área de estudo apresenta valores em todos os postos analisados superiores a $1000 \mathrm{~mm}$, com um valor médio de $1.462 \mathrm{~mm}$. Estes elevados valores de ETP resultam em parte das elevadas temperaturas a que esta submetida a região nordeste, considerada por Conti (2003) como faixa privilegiada em relação ao recebimento de radiação solar, a concentração de calor e de excedente energético. 
Uma análise comparativa entre os valores médios de precipitação e evapotranspiração potencial permite inferir o significativo déficit hídrico, superior a $400 \mathrm{~mm} /$ ano no Núcleo de São Raimundo Nonato.

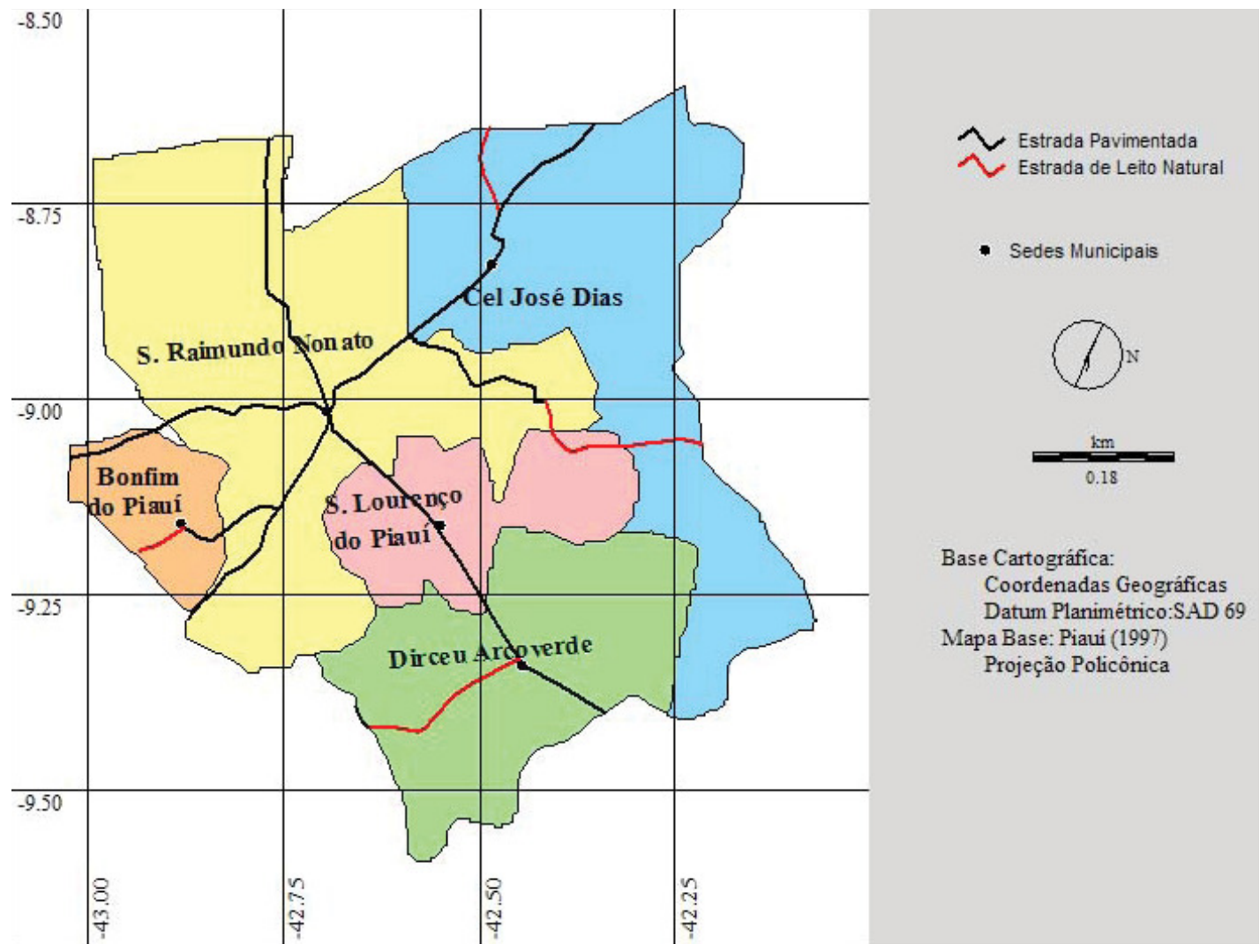

Figura 1 - Localização da área de estudo e distribuição espacial dos municípios integrantes do Núcleo de São Raimundo Nonato - Piauí

O índice de aridez (IA) proposto pelo UNEP (1991) para a identificação das terras secas suscetíveis a desertificação foi aplicado e revelou níveis diferenciados de aridez para a área de estudo com valores de IA variando de $<0,20$ a $<0,65$, com predominância de valores entre 0,20 a 0,50, permitindo o enquadramento climático da área na tipologia semiárida. Os valores do Índice Efetivo de Umidade (Thornthwaite \& Mather, 1955) obtidos variaram de -33 a -60 reforçando a ocorrência de um clima semiárido para a área de estudo. O coeficiente de variação variou de $28,2 \%$ a 43,9\%, evidenciando assim a fragilidade climática e consequentemente ecológica da área de estudo.

A variedade litológica, aliada ao condicionante climático favorecem a ocorrência diferenciada de solos (Latossolos (61,9\%), Argissolos (17,4\%), Neossolos Litólicos (16,7\%), Neossolos Regolíticos $(3,6 \%)$ e ainda os Luvissolos $(0,4 \%)$, sobre os quais identifica-se a presença de cobertura vegetal xerofítica, com caducifólia sazonal representada pelas caatingas.

\section{Procedimentos metodológicos e técnicos}

O trabalho baseou-se em técnicas de sensoriamento remoto. Por meio destas, são fornecidas imagens de grandes áreas, muitas vezes de difícil acesso, a custo relativamente baixo e com certa periodicidade, o que potencializa sua utilização nos levantamentos dos diferentes tipos de cobertura das terras, bem como, nos estudos de degradação ambiental.

Estudos como os de Accioly et al. (2002 e 2005), Campos et. al (2004), Franco et al. (2007), Sousa et al. (2008), Fernandes et al. (2009), Lopes et al. (2010), Rosemback et al. (2010) e Sá et al. (2010), constituem referência no emprego de técnicas de sensoriamento remoto para análise da dinâmica da cobertura vegetal e avaliação de áreas degradadas/desertificadas. 
Silva \& Silva (2011) com o emprego de técnicas de geoprocessamento e sensoriamento remoto combinado a índices de paisagem analisaram a cobertura vegetal de Lucena entre os anos de 1970 e 2005. Constataram significativa fragmentação de áreas de mata em detrimento especialmente do cultivo de cana-de-açucar. Em 1970, havia cerca de 2.150 ha de matas na área estudada, em 2005 a área era de apenas 769 ha, uma redução segundo os autores de 1.381 ha de área de mata em 35 anos.

Barbosa et al.(2009) estudou a evolução da cobertura vegetal e uso agrícola do solos do município de Lagoa Seca- PB. O estudo baseou-se em fotos aéreas de 1984 e imagens do Landsat TM3, TM4 e TM5 de 1989, aliada a levantamentos através de sistema de posicionamento global (GPS), 2001. Identificaram 7 fisionomias diferenciadas de cobertura vegetal e uso agrícola. Consideram que o emprego das tecnologias de SIG é fundamental para o resgate do passado e elaboração de planejamento futuro das paisagens.

Sá et al. (2010) analisaram a cobertura vegetal de parte da região do Araripe Pernambucano a partir do uso de imagens digitais do sensor Thematic Mapper (TM) do satélite LANDSAT 5, datadas de 21/09/2008. Estabeleceram 8 classes de NDVI e de cobertura vegetal e uso da terra. Afirmam que o mapeamento da cobertura vegetal e uso da terra na região do Araripe Pernambucano constitui ferramenta bastante útil para o planejamento do espaço territorial da região da Chapada do Araripe.

Para análise de mudanças nos padrões de NDVI, foram utilizadas as bandas espectrais 3 e 4 do Landsat 5 TM referentes aos anos de 1987 e 2007. Estas bandas apresentam valores de refletância nos comprimentos de onda do vermelho e infravermelho próximo. Para o cálculo do NDVI utilizou-se o utilitário VEGINDEX do software IDRISI 3.2.

Na restituição de padrões de tipos de coberturas das terras do ano de 1987, foram utilizadas as bandas espectrais 2, 3, 4 e 5, considerando a resposta espectral dos alvos, aliada a conhecimentos relativos a clima, solo e relevo da área de estudo conforme sugeridos por Beltrame (1994).

Para o ano de 2007, as análises das imagens foram realizadas a partir da composição das bandas espectrais 2, 3, 4 e 5, do Landsat 5 TM combinadas com trabalhos de campo. As imagens foram adquiridas gratuitamente no site do Instituto Nacional de Pesquisas Espaciais (INPE). As imagens empregadas com os respectivos pontos, órbitas, datas de passagem do satélite, sensor e resolução estão listadas no Quadro 1.

Quadro 1-Características das imagens utilizadas para identificação de níveis de NDVI e tipologias de cobertura das terras na área de estudo

\begin{tabular}{|c|c|c|c|c|c|c|c|}
\hline \multicolumn{4}{|c|}{1987} & \multicolumn{4}{|c|}{2007} \\
\hline $\begin{array}{l}\text { Ponto } \\
\text { /órbita }\end{array}$ & Datas & Sensor & Resolução & $\begin{array}{l}\text { Ponto } \\
\text { /órbita }\end{array}$ & Datas & Sensor & Resolução \\
\hline $219 / 66$ & $\begin{array}{l}\text { 09/08/1987; } \\
\text { 06/06/1987 }\end{array}$ & $\begin{array}{c}\text { Landsat } 5 \\
\text { TM }\end{array}$ & 30 metros & $219 / 66$ & $01 / 09 / 2007$ & $\begin{array}{c}\text { Landsat } 5 \\
\text { TM }\end{array}$ & 30 metros \\
\hline $218 / 66$ & $\begin{array}{l}\text { 03/09/1987; } \\
\text { 30/05/1987 }\end{array}$ & $\begin{array}{c}\text { Landsat } 5 \\
\text { TM }\end{array}$ & 30 metros & $218 / 66$ & $29 / 09 / 2007$ & $\begin{array}{c}\text { Landsat } 5 \\
\text { TM }\end{array}$ & 30 metros \\
\hline $218 / 67$ & $\begin{array}{c}\text { 03/09/1987; } \\
30 / 05 / 1987\end{array}$ & $\begin{array}{c}\text { Landsat } 5 \\
\text { TM }\end{array}$ & 30 metros & $218 / 67$ & $26 / 09 / 2007$ & $\begin{array}{c}\text { Landsat } 5 \\
\text { TM }\end{array}$ & 30 metros \\
\hline
\end{tabular}

As imagens orbitais adquiridas no INPE foram importadas para o software IDRISI 3.2, em seguida foram georreferenciadas no sistema de coordenadas geográficas (latitude-longitude) a partir do método imagem - imagem. Após o registro das imagens com o uso do utilitário MOSAIC as imagens foram mosaicadas, em seguida com o utilitário OVERLAY a imagem foi recortada considerando os limites geográficos da área de estudo.

O mapeamento da dinâmica da cobertura vegetal e uso do solo foi realizado a partir do método de Classificação Supervisionada, do tipo pixel a pixel objetivando definir regiões homogêneas. 
A classificação é dita supervisionada, quando o analista, a partir do conhecimento da área ou por inferência, relaciona áreas da imagem com as classes de cobertura da terra que deseja separar (CRÓSTA, 2001).

O enquadramento de um pixel a uma determinada classe é feito por vários métodos, levando-se em consideração os valores de níveis de cinza nas várias bandas utilizadas (neste estudo, utilizaram-se as bandas 2, 3, 4 e 5) .O método utilizado no presente estudo para enquadramento dos pixels foi o MAKESIG do IDRISI 3.2, associando a cada pixel da imagem a uma assinatura similar. Na seqüência utilizou-se o módulo MAXLIKE do IDRISI 3.2, com o emprego do método da máxima verossimilhança, para atribuir a cada pixel identificado sua respectiva assinatura espectral, gerando uma imagem classificada.

As fácies de cobertura vegetal foram identificadas através de uma chave de interpretação considerando as variáveis forma, textura, tonalidade, tamanho e localização.

$\mathrm{Na}$ análise econômica da área foram empregados dados de Pesquisa Agropecuária Municipal (PAM) (1989, 1995, 2001 e 2006) e Pesquisa Pecuária Municipal (PPM) (1991, 1995, 2001 e 2006).

\section{RESULTADOS}

\section{Dinâmica da cobertura das terras nos anos de 1987 e 2007}

As fácies de cobertura das terras identificadas, considerando a estratificação (distribuição das plantas conforme suas alturas) e ainda a densidade entre as espécies, foram: caatinga arbórea, caatinga arbustiva densa, caatinga arbustiva aberta e agropecuária + solo exposto. $\mathrm{O}$ fato de as áreas utilizadas para agricultura e pecuária na estação seca exibirem em sua maioria a presença de solo exposto identificadas nas imagens como sendo as áreas mais claras, justifica a junção destas duas categorias em uma única classe.

A Figura 2 apresenta a distribuição espacial dos tipos de cobertura vegetal e uso das terras para os anos de 1987 e 2007. Com base nesta Figura, constata-se para o ano de 1987 a seguinte distribuição espacial entre as classes: 12,0\% Catinga Arbórea, 24,9\% Caatinga Arbustiva Densa, 32,0\% Caatinga Arbustiva Aberta e 31,1\% Agropecuária + Solo exposto. Para o ano de 2007 a distribuição das fácies apresentadas anteriormente e a seguinte: 4,9\%,39,3\%, 29,0\% e 26,8\% respectivamente.

A avaliação da detecção de mudanças entre os tipos de cobertura vegetal e uso das terras entre os anos de 1987 e 2007, objetivou identificar e avaliar processos de degradação e/ou recuperação ambiental na área de estudo. A avaliação destas mudanças pode ser constatada na Tabela 1, que apresenta as modificações nos de tipos de cobertura identificados em 1987, com as respectivas alterações sofridas pelos mesmos em 2007.

Uma análise dos dados constantes na Tabela 1 permite inferir que:

- Do total de $835,7 \mathrm{Km} 2$, que representava a mancha de caatinga arbórea identificada em 1987 , apenas $17,7 \%$ permaneceu nesta classe em $2007,65,4 \%, 11,2 \%$ e $5,7 \%$ passaram para as classes de caatinga arbustiva densa, caatinga arbustiva aberta e agropecuária + solo exposto, evidenciando assim, desequilíbrios/degradação que podem resultar de variações nas condições climáticas da área e/ou de desmatamentos.

- Para o tipo identificado em 1987 como caatinga arbustiva densa, constatou-se uma recuperação vegetacional em 3,5\% da área que passou em 2007 a categoria de caatinga arbórea, $59,5 \%$ da área manteve-se recoberta por caatinga arbustiva densa, $24,8 \%$ e $12,2 \%$ passaram para as classes de caatinga arbustiva aberta e agropecuária + solo exposto.

- Na classe caatinga arbustiva aberta também podem ser evidenciadas modificações substanciais no sentido de recuperação vegetacional, pois em 2,9\% e 31,4\% da área desta mancha a vegetação passou em 2007 para as classes de arbórea e arbustiva densa respectivamente 


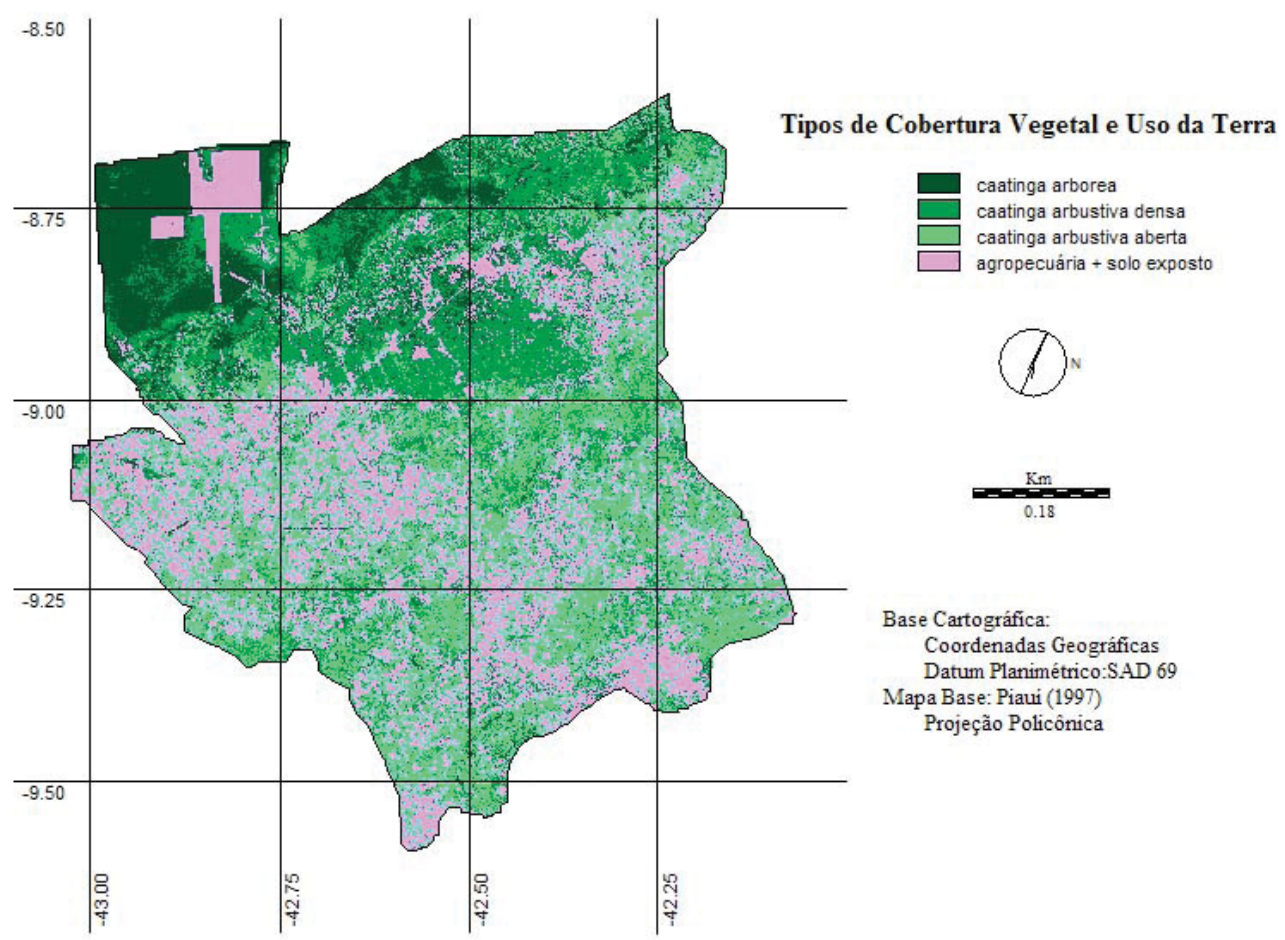

Formações Vegetais e Uso da Terra no Núcleo de São Raimundo Nonato, 2007

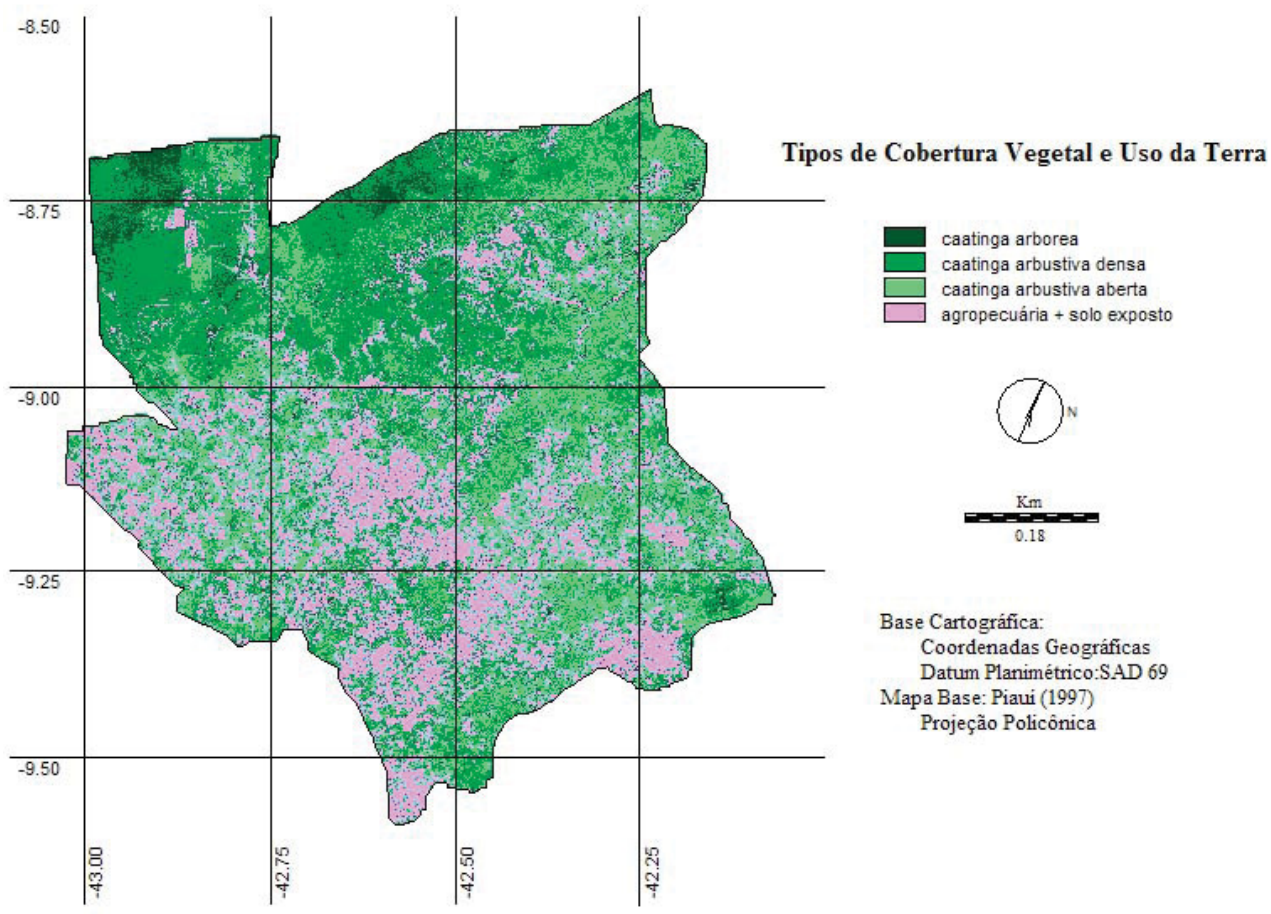

Figura 2 - Formações Vegetais e Uso da Terra no Núcleo de S. Raimundo Nonato. Comparação entre os anos de 1987 e 2007. 
evidenciando assim a ocorrência de sucessão ecológica. Os dados obtidos revelam que 40,4\% desta classe manteve-se como caatinga arbustiva aberta e $25,4 \%$, passou a categoria agropecuária + solo exposto, indicando aumento de degradação/desertificação.

- Mudanças substanciais também foram observadas na categoria agropecuária + solo exposto. Em 2007 este mosaico apresentou 3,3\%, 21,3\% e 27,4\% dos seguintes tipos de cobertura vegetal: caatinga arbórea, caatinga arbustiva densa e caatinga arbustiva aberta. Apenas $48,0 \%$ permaneceu como agropecuária + solo exposto o que permite inferir diferentes estágios de sucessão ecológica secundária, com consequente melhorias na dinâmica do ambiente.

Tabela 1 - Distribuição absoluta e relativa dos tipos cobertura vegetal e uso das terras na imagem de 1987 e sua dinâmica na imagem de 2007

\begin{tabular}{|c|c|c|c|c|c|c|}
\hline \multicolumn{3}{|c|}{ Tipos de cobertura das terras (1987) } & \multicolumn{4}{|c|}{ Dinâmica dos tipos de cobertura das terras (2007) } \\
\hline & rbórea & & \multirow{2}{*}{$\begin{array}{c}\text { Arbustiva } \\
\text { Aberta }\end{array}$} & \multicolumn{2}{|c|}{$\begin{array}{l}\text { Agropecuária } \\
\text { +solos exposto }\end{array}$} & \multirow[b]{2}{*}{48,0} \\
\hline \multirow{2}{*}{ Arbórea } & Área $\left(\mathrm{Km}^{2}\right)$ & 835,7 & & 546,8 & 93,6 & \\
\hline & $\%$ & 12,0 & 17,7 & 65,4 & 11,2 & 5,7 \\
\hline \multirow{2}{*}{ Arbustiva Densa } & Área $\left(\mathrm{Km}^{2}\right)$ & 1741,2 & 60,7 & 1035,7 & 431,1 & 213,7 \\
\hline & $\%$ & 24,9 & 3,5 & 59,5 & 24,8 & 12,2 \\
\hline \multirow{2}{*}{ Arbustiva Aberta } & Área $\left(\mathrm{Km}^{2}\right)$ & 2235,6 & 64,6 & 701,0 & 903,0 & 567,0 \\
\hline & $\%$ & 32,0 & 2,9 & 31,4 & 40,4 & 25,3 \\
\hline \multirow{2}{*}{ Agropecuária } & Área $\left(\mathrm{Km}^{2}\right)$ & 2175,2 & 70,8 & 463,4 & 596,8 & 1044,2 \\
\hline & $\%$ & 31,1 & 3,3 & 21,3 & 27,4 & 48,0 \\
\hline \multirow{2}{*}{$\begin{array}{l}\text { Vegetação no ano de } \\
2007\end{array}$} & Área $\left(\mathrm{Km}^{2}\right)$ & 6887,7 & 343,4 & 2746,9 & 2024,5 & 1872,9 \\
\hline & $\%$ & 100,0 & 4,9 & 39,3 & 29,0 & 26,8 \\
\hline
\end{tabular}

O Gráfico da Figura 3 permite visualizar a distribuição dos tipos de cobertura vegetal e uso das terras nos anos estudados e a conseqüente melhoria na proteção oferecida pela vegetação.

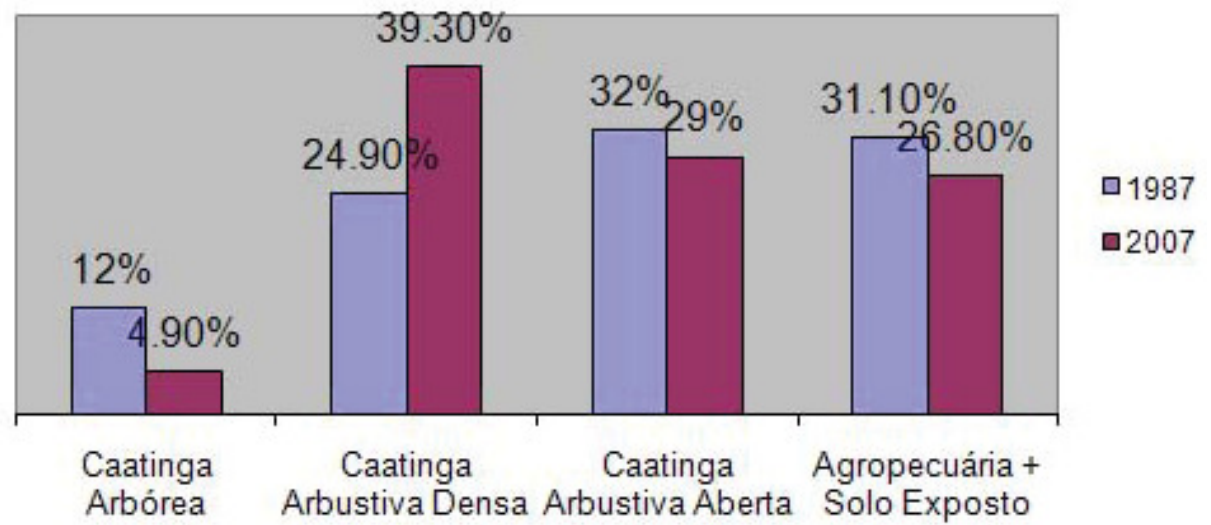

Figura 3 - Valores percentuais dos tipos de cobertura vegetal e uso do solo nos anos de 1987 e 2007 para o Núcleo de São Raimundo Nonato

Constata-se uma coerência nos dados obtidos na pesquisa com os encontrados por Lemos (2003). Este autor, baseado no porte (altura e diâmetro), caracterizou um hectare de caatinga do Parque Nacional Serra da Capivara. Concluiu que dos 5.827 indivíduos amostrados $(73,6 \%)$ do total apresentavam de 2,1 a 5,0 metros, apenas 22 indivíduos $(0,37)$ ultrapassaram 8,0 metros de altura e $26,03 \%$ apresentaram uma altura media de 3,5 metros. Estes dados confirmam o predomínio de uma caatinga com fisionomia arbustiva com indivíduos bastante ramificados na área de estudo 
e a presença de algumas árvores emergentes esparsas. Freitas (2007) afirma ser o predomínio de estratos arbustivos um sinal de possível sucessão secundária na área de estudo.

\section{Dinâmica do NDVI nos anos de 1987 e 2007}

O Índice de Vegetação por Diferença Normalizada varia de -1 a 1, sendo que quanto mais próximo de 1 maior o vigor da vegetação, mais densa a cobertura vegetal e maior a atividade fotossintética (SANTOS; NEGRI, 1997).

Os valores de NDVI estimados para a área de estudo foram reclassificados em seis classes: alta, muito alta, moderadamente baixa, baixa, muito baixa e solo exposto, representando os diferentes graus de proteção oferecidos pela cobertura vegetal ao solo. A Figura 4 apresenta a espacialização da variabilidade do NDVI na área de estudo para os meses de agosto e setembro do ano de 1987 e setembro 2007 (Figura 4), meses que caracterizam a estação seca na área de estudo. A Tabela 2 apresenta a distribuição absoluta e relativa dos valores de NDVI por classes para os anos considerados.

Tabela 2 - Valores absolutos e relativos de NDVI para o Núcleo de São Raimundo Nonato nos anos 1987 e 2007, com as respectivas classes de proteção

\begin{tabular}{|c|c|c|c|c|c|}
\hline \multirow{2}{*}{ Classes de Proteção } & \multirow[b]{2}{*}{$\begin{array}{c}\text { Intervalos de } \\
\text { NDVI }\end{array}$} & \multicolumn{2}{|c|}{ Área no Nível $\left(\mathrm{km}^{2}\right)$} & \multicolumn{2}{|c|}{ \% da Área Total no Nível } \\
\hline & & 1987 & 2007 & 1987 & 2007 \\
\hline Alta & 0,8 a 1,0 & 0,12 & 0,12 & --- & --- \\
\hline Moderadamente alta & $0,6 a<0,8$ & 0,28 & 0,22 & --- & --- \\
\hline Moderadamente Baixa & $0,4 a<0,6$ & 1,23 & 1,23 & --- & --- \\
\hline Baixa & $0,2 a<0,4$ & 223,56 & 51,87 & 3,2 & 0,7 \\
\hline Muito Baixa & $>0 a<0,2$ & 5018,33 & 6007,93 & 71,8 & 86,0 \\
\hline
\end{tabular}

Pela Tabela 2 constata-se não ter havido alterações nos valores de NDVI nas classes Alta e Moderadamente Baixa. Na classe Moderadamente Alta houve um pequeno aumento da ordem de $0,6 \mathrm{~km} 2$.

Mudanças mais significativas são constatadas nas classes de NDVI baixo, muito baixo e solo exposto. Houve decréscimo nas classes baixo de $3,2 \%$ para $0,7 \%$; a classe muito baixa aumentou de $71,8 \%$ para $86,7 \%$ e na classe solo exposto verificou-se redução de $25 \%$ para $13,3 \%$.

A redução de áreas de solo exposto e o consequente aumento da classe de proteção de NDVI muito baixa $(0>$ a 0,2$)$, representado por um estrato herbáceo também pode ser usado como indicador de uma possível sucessão secundária na área de estudo.

De acordo com os dados da Tabela anterior, pode-se afirmar que de modo geral houve melhoria nos níveis de proteção vegetal na área de estudo entre os anos analisados, a proteção que em 1987 era de $15,7 \%$ passou para 17,5\% em 2007.

\section{Dinâmica dos indicadores econômicos}

A Tabela 3 apresenta uma síntese da dinâmica agrícola do Núcleo de São Raimundo Nonato para os anos de 1989 e 2006 considerando as áreas destinadas a culturas temporárias e permanentes. 
Índice de Vegetação Normalizado (NDVI) do Núcleo de S. Raimundo Nonato

Dados da estação seca - Imagens de Agosto / Setembro de 1987

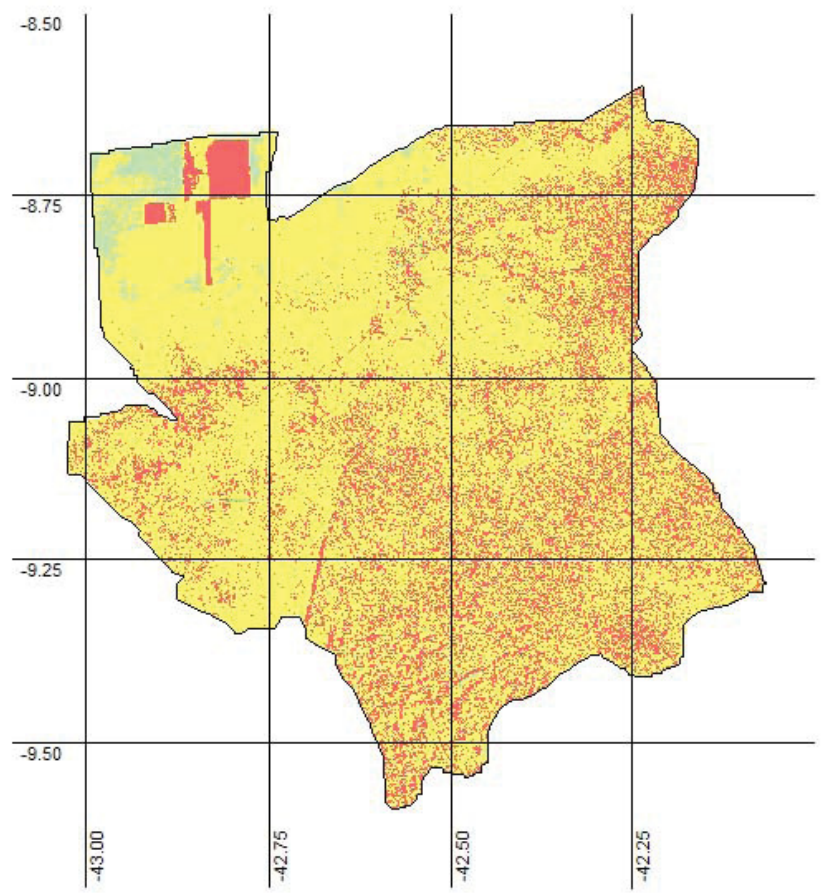

Classes de NDVI

0.8 a 1.0 (Alta)

0.6 a $<0.8$ (Medianamente Alta)

0.4 a $<0.6$ (Moderadamente Baixo)

$0.2 \mathrm{a}<0.4$ (Baixo)

$>0 \mathrm{a}<0.2$ (Muito Baixo)

0 (Solo Exposto)

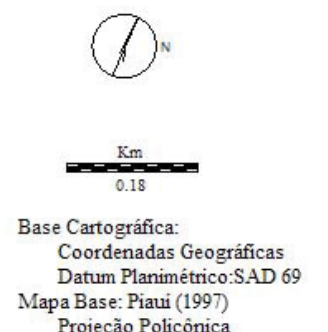

Índice de Vegetação Normalizado (NDVI) do Núcleo de S. Raimundo Nonato

Dados da estação seca - Imagem de Setembro de 2007

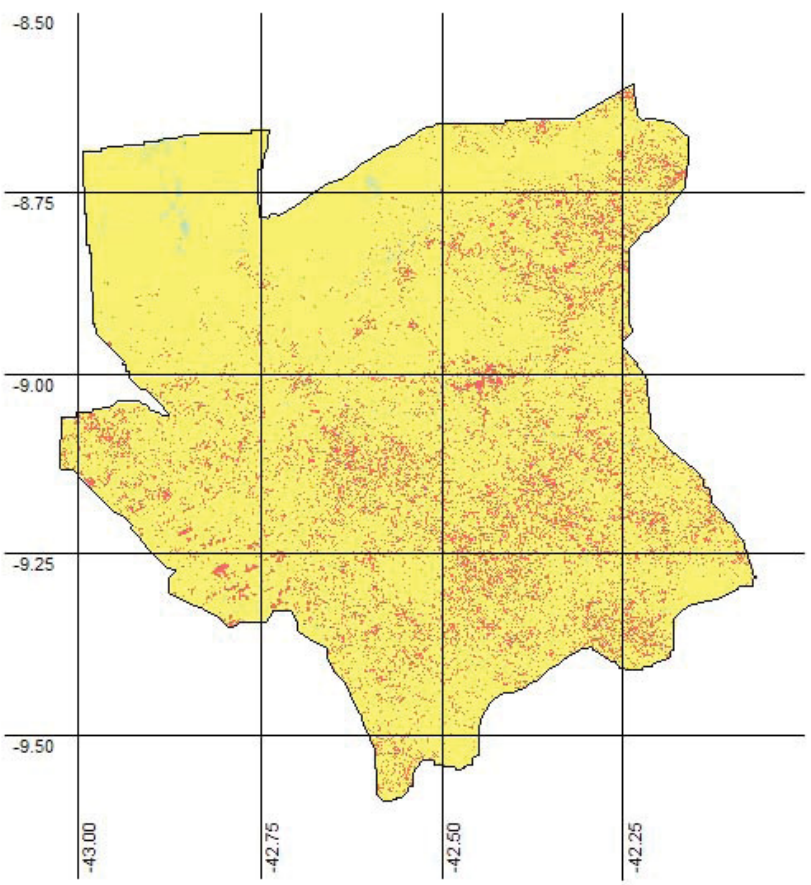

Classes de NDVI

0.8 a 1.0 (Alta)

0.6 a $<0.8$ (Medianamente Alta) $0.4 \mathrm{a}<0.6$ (Moderadamente Baixo)

$0.2 \mathrm{a}<0.4$ (Baixo)

$>0$ a $<0.2$ (Muito Baixo)

0 (Solo Exposto)
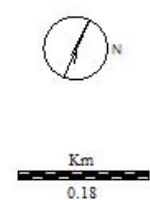

Base Cartográfica:

Coordenadas Geográficas

Datum Planimétrico:SAD 69

Mapa Base: Piaui (1997)

Projeção Policônica

Figura 4 - Índice de Vegetação Normalizado (NDVI) do Núcleo de S. Raimundo Nonato.

Comparação entre fim da estação chuvosa (Maio) e estação seca (Agosto / Setembro) do ano de 1987

De acordo com a Tabela 3, as áreas destinadas ao plantio de culturas temporárias apresentaram uma queda significativa, passando de 57.100 hectares em 1989 para apenas 17.909 hectares em 2006, o que significa uma queda de $68,6 \%$, com consequente redução da degradação, o que possibilitou o aumento da proteção oferecida pela cobertura vegetal "natural", que ao invés de ser removida e substituída anualmente por culturas temporárias permanecerá na área diminuindo sobremaneira os processos erosivos e a consequente degradação da terra. A tese da diminuição da degradação 
na área de estudo também é reforçada quando se observa o significativo aumento das culturas permanentes (cajucultura), que aumentou em 60,8\% entre os anos de 1989 e 2006 . O aumento das culturas permanentes promove maior proteção por parte da cobertura vegetal aos solos, reduzindo sobremaneira os processos degradacionais.

Tabela 3 - síntese da variação das áreas plantadas (culturas temporárias e permanentes) entre os anos de 1989 e 2006 no Núcleo de São Raimundo Nonato

\begin{tabular}{l|c|c|c|c|}
\hline \multirow{2}{*}{ Culturas } & \multicolumn{2}{|c|}{ Área Plantada (ha) } & \multicolumn{2}{c}{ Variação entre 1989 e 2006} \\
\cline { 3 - 5 } & & & & \multicolumn{2}{c|}{ Conseqüência } \\
\cline { 5 - 5 } & 1989 & 2006 & Percentagem & Redução da degradação/Aumento da proteção \\
\hline Temporárias & 57.100 & 17.909 & Redução de 68,6 & Aumento na Proteção /Redução da degradação \\
\hline Permanente & 7.800 & 19.900 & Aumento de 60,8 & \\
\hline
\end{tabular}

A pecuária extensiva historicamente tem-se constituído a principal atividade econômica no Núcleo de São Raimundo Nonato. No entanto, ao longo dos anos esta atividade vem sofrendo algumas modificações que podem ser constatadas a partir dos dados constantes na Tabela 4, que apresenta uma síntese da variação dos rebanhos (bovino, caprino e ovino) entre os anos de 1991 e 2006 no Núcleo de São Raimundo Nonato, considerando o número de cabeças e as unidades animais.

A partir dos dados da Tabela 4, constata-se redução de 43,5\% em termos de unidade animal e de $23,9 \%$ no número de cabeças de animal para os rebanhos bovino, caprino e ovino entre os anos de 1991 e 2006. Estes dados reforçam a tese da redução da degradaçãoldesertificação na área de estudo.

Tabela 4 - Síntese da variação dos rebanhos (bovino, caprino e ovino) entre os anos de 1991 e 2006 no Núcleo de São Raimundo Nonato

\begin{tabular}{|c|c|c|c|c|c|c|c|c|}
\hline \multirow{4}{*}{ Variáveis } & \multicolumn{8}{|c|}{ Rebanho } \\
\hline & \multicolumn{2}{|c|}{ Bovinos (B) } & \multicolumn{2}{|c|}{ Caprinos (C) } & \multicolumn{2}{|c|}{ Ovinos (O) } & \multicolumn{2}{|c|}{ Totais $(B+C+O)$} \\
\hline & \multicolumn{8}{|c|}{ Anos } \\
\hline & 1991 & 2006 & 1991 & 2006 & 1991 & 2006 & 1991 & 2006 \\
\hline Cabeças & 49.630 & 24.276 & 142.962 & 97.743 & 76.017 & 82.321 & 268.609 & 204.340 \\
\hline Unidade Animal & 49.630 & 24.276 & 9.531 & 6.516 & 5.068 & 5.489 & 64.229 & 36.281 \\
\hline \multirow[t]{3}{*}{$\begin{array}{l}\text { Variação entre } \\
1991 \text { e } 2006\end{array}$} & & & & & \multicolumn{2}{|c|}{ Percentagem/ Cabeças } & \multicolumn{2}{|c|}{ Redução de $23,9 \%$} \\
\hline & \multicolumn{2}{|c|}{$\begin{array}{l}\text { Percentagem/unidade } \\
\text { animal }\end{array}$} & \multicolumn{3}{|c|}{ Redução de 43,5\% } & & & \\
\hline & \multicolumn{2}{|c|}{ Conseqüência } & \multicolumn{3}{|c|}{$\begin{array}{l}\text { Redução da degradação/Aumento da pro- } \\
\text { teção }\end{array}$} & & & \\
\hline
\end{tabular}

\section{CONSIDERAÇÕES FINAIS}

- Confirma-se a importância do emprego de técnicas de sensoriamento remoto na avaliação espaço-temporal de mudanças de cobertura das terras, para fins de analises da degradação ambiental.

- A metodologia adotada mostrou-se eficiente, pois a utilização de imagens orbitais Landsat-5 combinadas com técnicas de geoprocessamento, dados agropecuários e inspeções a campo evidenciaram resultados bastante confiáveis. 
- Os resultados mostraram que houve decréscimo significativo da classe de cobertura das terras do tipo agricultura+solos exposto, esta decresceu de 31,1\% em 1987 para 26,8\% em 2007 , já na classe caatinga arbustiva densa constatou-se incremento de $24,9 \%$ para $39,3 \%$.

- Os dados de NDVI também evidenciaram decréscimo da classe solo exposto que em 1987 era de $25 \%$ e em 2007 decaiu para $13,3 \%$. Na classe de proteção muito baixa houve incremento passou de $71,8 \%$ em 1987 para 86\% em 2007.

- As mudanças constatadas nas análises das imagens orbitais entre os anos de 1987 e 2007 no Núcleo de São Raimundo Nonato revelam uma melhora em termos de proteção oferecida pela cobertura vegetal, resultado da ocorrência de uma possível sucessão ecológica secundária, que sugere uma melhora na condição ambiental, com decréscimos da degradação/desertificação.

- Os resultados pertinentes à análise econômica relativos aos dados de produção agrícola e rebanhos indicam redução no desenvolvimento destas atividades, corroborando os resultados obtidos na análise da cobertura das terras e de NDVI e sugerindo uma diminuição da degradação/desertificação na área de estudo.

- Com base nos resultados aqui obtidos sugere-se a realização de pesquisa para esclarecer a relação entre as variações, entre 1987 e 2007, dos níveis dos diferentes tipos de cobertura vegetal e tipos de uso da terra.

\section{REFERÊNCIA BIBLIOGRÁFICA}

ACCIOLY, L.J.O.; GARCON, E.A.M.; BARROS, M.R.O.; \& BOTELHO, F. Avaliação de alvos em áreas sob desertificação no semiárido paraibano com base nos sensores Hyperion e LANDSAT7 ETM+. In: Anais XII Simpósio Brasileiro de Sensoriamento Remoto, Goiânia, p. 347-353, Abril, 2005.

ACCIOLY, L.J.O.; PACHECO, A.; COSTA, T.C.C.; LOPES, O.F.; \& OLIVEIRA, M.A.J. Relações empíricas entre a estrutura da vegetação e dados do sensor TM/LANDSAT. Revista Brasileira de Engenharia Agrícola e Ambiental, Campina Grande, vol. 6, nº 3, p. 492-498, 2002.

BARBOSA, I; S.; ANDRADE. L. A.; \& ALMEIDA, J. A. P. Evolução da cobertura vegetal e uso agrícola do solo no município de Lagoa Seca, PB. Revista Brasileira de Engenharia Agrícola e Ambiental. Campina Grande, v.13, n 5, p. 614-622, 2009.

BELTRAME, A.V. Diagnóstico do meio físico de bacias hidrográficas: modelo e aplicação. Florianópolis: Ed. da UFSC, 1994.

BERTRAND, G. Paisagem e Geografia Física global: esboço metodológico. RA’EGA, Curitiba, nº 8, p. $141-152,2004$.

BRASIL. Departamento Nacional de Produção Mineral. Projeto Radam. Levantamento de Recursos Naturais: Parte das Folhas SC.23 - Rio São Francisco e SC.24 Aracaju. Rio de Janeiro, Vol.1, 1973.

BRASIL. Ministério do Meio Ambiente. Programa de ação Nacional de Combate à desertificação e Mitigação dos Efeitos da Seca, PAN-BRASIL. Edição comemorativa dos 10 anos da Convenção das Nações Unidas de Combate à Desertificação e Mitigação dos Efeitos da Seca-CCD. Brasília: MMA, 2004. 225p. CAMPOS, S.; SILVA, M.; PIROLI, E. L.; CARDOSO, L.G. BARROS, Z.X. Evolução do uso da terra entre 1996 e 1999 no município de Botucatu - SP. Engenharia Agrícola, Jaboticabal, vol. 24, $\mathrm{n}^{\mathrm{o}}$ 1, p. 211-218, jan/abr. 2004.

CRÓSTA, A.P. Processamento digital de imagens de sensoriamento remoto. Campinas: UNICAMP, $2001.170 \mathrm{p}$.

CONTI, José Bueno. A desertificação como forma de degradação ambiental no Brasil. In: RIBEIRO, W.C. (org.). Patrimônio Ambiental Brasileiro. São Paulo: EDUSP, 2003.

FERNANDES, L. R.; ALMEIDA, A.M.; DUARTE, C. R. Evolução da "cobertura vegetal"no município de Carnaúba dos Dantas - região do Seridó/RN. In: Anais XIV Simpósio Brasileiro de Sensoriamento Remoto, XIV, 2009, Natal, 25-30 de abril, p.2721-2728, 2009. 
FRANCO, E.S.; LIRA, V. M.; FARIAS, M. S.S.; PORDEUS, R.V.; LIMA, V.L.A. Uso de imagens TM/ Landsat -5 na identificação da degradação ambiental na microbacia hidrográfica em Boqueirão - PB. Campo-território: revista de geografia agrária, Minas Gerais, vol. 2, nº 3, p. 79-88, fev., 2007.

FREITAS, M.W.D.de. Estudo integrado da paisagem no sertão pernambucano (NE-Brasil) com o uso de sistemas de informação geográfica e sensoriamento remoto. 2007. 191 f. Dissertação (Mestrado em sensoriamento remoto) - Instituto Nacional de Pesquisas Espaciais, Inpe, São José dos Campos, 2007.

INSTITUTO BRASILEIRO DE GEOGRAFIA E ESTATISTICA - IBGE. Pesquisa

Agropecuária Municipal - Piauí - anos de 1989, 1995, 2001 e 2006. Rio de Janeiro.

INSTITUTO BRASILEIRO DE GEOGRAFIA E ESTATISTICA - IBGE. Pesquisa

Pecuária Municipal anos Piauí - de 1991, 1995, 2001 e 2006. Rio de Janeiro.

LEMOS, J. R. Fitofisionomia de um hectare de caatinga no Parque Nacional Serra da Capivara, Estado do Piauí, Brasil. Brasil Florestal, Brasília, nº 75, 2003.

LOPES, H.;CANDEIAS, A.L.B.; ACCIOLY, L.J.O.; SOBRAL, M. do C.M. \& PACHECO, A.P. Parâmetros biofísicos na detecção de mudanças na cobertura e uso do solo e,m bacias hidrográficas. Revista Brasileira de Engenharia Agrícola e Ambiental, v. 14, n. 11, p.1210-1219, 2010.

OLIVEIRA, T. H.; SILVA, J.S.; SILVA, C.A.V.; SANTIAGO, M.M.; MENEZES, J.B.;SILVA, H.A. \& PIMENTEL, R. M. M. Avaliação da Cobertura Vegetal e do Albedo da Bacia Hidrográfica do Rio Moxotó com Imagens do Satélite Landsat 5. In: Anais XIV Simpósio Brasileiro de Sensoriamento Remoto, Natal, Brasil, 25-30 abril 2009.

ROSEMBACK, R.; FERREIRA, N.J.; SHIMABUKURO, Y.E.; CONFORTE, J.C. Análise da dinâmica da cobertura vegetal na região sul do Brasil a partir de dados MODIS/TERRA. Revista Brasileira de Cartografia, Rio de Janeiro, nº 62, Edição Especial 2, p.401-416, 2010.

SÁ, I. I. S.; GALVÍNCIO, J. D.; MOURA, M.S.B.; \& SÁ, I.B. Cobertura vegetal e uso da terra na região Araripe pernambucana. Mercator, Fortaleza, vol.9, nº 19, mai./ago., 2010.

SILVA, V.C.L. \& SILVA R. M. SILVA. Análise da cobertura vegetal em Lucena entre 1970/2005 usando ecologia da paisagem, Sig e sensoriamento remoto. Caminhos de Geografia, Uberlândia, $V^{o} 12, n^{\circ} 37, p$ 8-20, 2011.

SANTOS, P.; NEGRI, A. J. A comparasion of the normalized difference vegetation index and rainfall for the Amazon and northeastern Brazil. Journal of applied meteorology, Washington, v. 36, n 7, p. 958-965, 1997.

SOUSA, R. F.; BARBOSA, M. P.; SOUSA JÚNIOR, S.P.; NERY, A.P ; LIMA, A.N. Estudo da evolução esapço-temporal da cobertura vegetal do município de Boa Vista - PB, utilizando geoprocessamento. Caatinga, Mossoró, vol. 21, n 3, p.22-30. Jun/agos. 2008.

SUDENE. Dados Pluviométricos Mensais do Nordeste: Estado do Piauí. Recife, 1990.

THORNTHWAITE, C.W \& J.R. MATHER. The Water Balance - Publications in Climatology. N. Jersey: Centerton, v. VIII, $n^{\circ} 1,1955$.

UNEP. Status of desertification and implementation of the United Nations Plan of Action to Combat Desertification. Nairóbi, 1991.

VASCONCELOS SOBRINHO, J. Metodologia para Identificação de Processos de Desertificação: Manual de Indicadores. Recife: SUDENE, 1978.

VIEIRA, N.M. Estudo geomorfológico das voçorocas de Franca - SP. 1978. 225 f. Tese (Doutorado em História) - Instituto de História e Serviço Social, Universidade Estadual Paulista, Franca, 1978.

Trabalho enviado em setembro de 2012

Trabalho aceito em novembro de 2012 